Mycologia, 100(1), 2008, pp. 20-30.

(C) 2008 by The Mycological Society of America, Lawrence, KS 66044-8897

\title{
Identification of novel genes associated with conidiation in Beauveria bassiana with suppression subtractive hybridization
}

Jiang $\mathrm{Wu}$

Hayley J. Ridgway

Margaret A. Carpenter

National Centre for Advanced Bio-Protection

Technologies, P.O. Box 84, Lincoln University,

Lincoln, New Zealand

Travis R. Glare

AgResearch Ltd., Private Bag 4749, Christchurch 8140, New Zealand

Abstract: The conidiation of the entomopathogenic fungus Beauveria bassiana (Hyphomycete) is a complex process that involves the stage- and cell-typespecific expression of hundreds of genes. The suppression subtractive hybridization method was used to target genes involved in conidiation. Seventeen genes were cloned that potentially were involved in conidia formation. Six of them demonstrated differential expression between conidial and vegetative cultures. Sequence analysis showed three cDNA fragments had similarity to known genes involved in either cellular metabolism or cell regulatory processes. The other cDNA fragments showed low or no similarity to any genes previously described. The fulllength cDNA and genomic sequence of a gene designated A43 was isolated. The A43 protein is composed of 180 amino acids and has $34 \%$ identity to a RNA-binding region-containing protein. The temporal expression pattern was consistent with the gene being involved in conidiation. The colony morphology of the A43 knock-out mutant had more floccus mycelium than the wild-type and also produced fewer conidia, indicating the A43 gene is involved in $B$. bassiana conidiation.

Key words: Beauveria bassiana, conidiation, SSH

\section{INTRODUCTION}

The entomopathogenic fungus Beauveria bassiana is a globally distributed Hyphomycete, strains of which infect a range of insects. Strains of B. bassiana have been used as the active agents in a number of biopesticides against a variety of agricultural pests, including whiteflies, beetles, grasshoppers and psyllids (de la Rosa et al 2000, Brownbridge et al 2001,

Accepted for publication 16 September 2007.

${ }^{1}$ Corresponding author. E-mail: jiang.wu@agresearch.co.nz or jiangwu2000@hotmail.com Tel: 6433259960.
Butt et al 2001). The fungus is a facultative saprophyte and there are reports of $B$. bassiana growing as a plant endophyte and interacting with plant roots (Wagner and Lewis 2000, Lewis et al 2001, White et al 2002).

Although a sexual stage is now known (Li et al 2001) most B. bassiana exist as asexual organisms, reproducing mainly through the production of single cell conidia. B. bassiana produce three single cell forms, aerial conidia, in vitro blastospores and submerged conidia in different conditions (Jeffs et al 1999). Aerial conidia are produced on the surface of solid medium by a process of hyphal extension, formation of phialides (rachis) and spore production. Aerial conidia usually are used for biological control agents because they are relatively resistant to varying environmental conditions and can be formulated to prolong shelf life. Aerial conidia contain a rodlet layer that results in a hydrophobic property (Holder and Keyhani 2005). Blastospores are produced in nutrient liquid medium. They are hydrophilic, and they germinate and grow at much higher rate than aerial conidia. Submerged conidia are produced in defined liquid medium (Thomas et al 1987). They are also hydrophilic, showing a rough surface morphology. Submerged conidia represent an important developmental stage for growth in a limited nutrient medium.

Infections of insects are usually initiated by the contact of conidia on the cuticle of insect hosts, followed by germination and penetration of the cuticle. The fungus multiplies in the haemocoel of the insect, eventually invading the whole body and causing death. Therefore most biopesticide applications are reliant on the production of conidia in bulk on artificial substrates, usually grains. Bulk production of the infective conidia can be inconsistent, with the most virulent strains capable of attenuation of sporulation. A better understanding of the genetics of conidiation in Beauveria may assist in consistent production of conidia. Most research has been focused on production method development and fermentation optimization to enhance sporulation (Wraight et al 2001, Kemp and Bidochka 2002). Little is known about the mechanism of sporulation in $B$. bassiana or the genes involved in conidiation. cDNA libraries from $B$. bassiana recently were generated from mRNA isolated from aerial conidia, blastospores and submerged conidia respectively. Approximately $40-45 \%$ of sequences in each library show no significant similarity or similarity to hypothetical 
proteins found in the NCBI database (Cho et al 2006), indicating the scarcity of fungal sporulation gene sequences in the GenBank.

Suppression subtractive hybridization $(\mathrm{SSH})$ is a method that uses a suppressive PCR to create cDNA libraries from the cDNA of two physiological states of an organism, such that only the genes differentially expressed in the two states are amplified (Diatchenko et al 1996, von Stein et al 1997). The SSH method has advantages over the traditional methods of selective amplification of differentially expressed sequences in that it enhances the probability of identification of gene expression of low-abundance transcripts (Gurskaya et al 1996). Herein we describe identification of genes involved in conidiation by using $\mathrm{SSH}$ to isolate cDNA fragments that are differentially expressed in conidia and vegetative mycelium. In addition a full gene sequence was isolated and its function partially characterised through gene disruption.

\section{MATERIALS AND METHODS}

Strains and media._-Escherichia coli strain DH5 $\alpha$ was used as a host for routine cloning. Agrobacterium tumefaciens strain EHA105, used for transformation of $B$. bassiana, was obtained from Lincoln University and was cultured in Luria broth (LB) and minimal medium (MM) with suitable antibiotics at $28 \mathrm{C}$ (de Groot et al 1998). B. bassiana F418 strain originally isolated from Sitona lepidus (Coleoptera: Curculionidae), obtained from the AgResearch (AgResearch Insect Pathogens Culture Collection, Lincoln, New Zealand). A conidial suspension was spread on potato dextrose agar (PDA) plates and grown at 26 C. Conidia were collected from 3-8 d PDA plates and washed with sterile $0.05 \%$ Tween 80 and the conidia suspension was filtered through a single layer of miracloth. The concentration of conidia was determined with a haemocytometer. Aliquots of this spore suspension were used for inoculum and for transformation.

Suppression subtractive hybridization construction.-Suppression subtractive hybridization ( $\mathrm{SSH}$ ) was performed with the PCR-select cDNA subtraction kit (BD Bioscience Clontech, Palo Alto, California). B. bassiana strain F418 was cultured on PDA plates for 3-5 d. Conidiophores and conidia were collected from the plates and the mRNA from this culture was used as a "tester" in the SSH. F418 mycelium was grown in $200 \mathrm{~mL}$ of potato dextrose (PD) broth inoculated with $10^{7}$ of conidia at $26 \mathrm{C}$ and $150 \mathrm{rpm}$ for $48 \mathrm{~h}$. After $48 \mathrm{~h} 200 \mathrm{~mL}$ of fresh PD was added into the culture, which was mixed, divided into two parts in flasks and grown $24 \mathrm{~h}$. After $24 \mathrm{~h}$ the step was repeated to synchronize mycelium to obtain young hyphae without conidia. The four flasks of mycelium were harvested by centrifugation at $3000 \mathrm{rpm}$ and $4 \mathrm{C}$ for $5 \mathrm{~min}$ and washed twice with sterile water. The mycelium was checked with a compound microscope to confirm no conidia were present. The mRNA from this mycelium was used as a "driver".
Amplification of the subtractive hybridization products was conducted with Hot-Master Taq DNA polymerase and following the Clontech protocol. The final PCR products were cloned into pGEM-T Easy vector (Promega, Madison, Wisconsin) and transformed into E. coli DH5 $\alpha$. The inserts were amplified by PCR with nested primers 1 and $2 R$ from the cDNA subtraction kit and PCR conditions followed the protocol. Amplified inserts were purified with PCR Kleen spin columns (BioRad, Hercules, California) and used as probes for Northern blots. The clones were cultured overnight for plasmid extraction and DNA sequencing.

DNA sequence analysis.-Subtraction clones were sequenced with T7 and SP6 primers, ABI BigDye terminator chemistry and an ABI3100 Genetic Analyzer (Applied Biosystems, USA). The DNA sequences were compared to the NCBI nucleotide and protein database by using BLASTX (Gish and States 1993, Altschul et al 1997) and to the fungal genome sequence database (Fungal Genome Initiative, The Broad Institute) by BLAST.

RNA isolation.-Fungal cells from mycelial and conidiating cultures were ground in liquid nitrogen. The total RNA was extracted with TRIzol reagent (Invitrogen, Carlsbad, California), and mRNA was purified with GenElute ${ }^{\mathrm{TM}}$ mRNA Miniprep Kit (Sigma-Aldrich, St Louis, Missouri) according to the manufacturer's protocol. The total RNA concentration was quantified with a spectrophotometer.

Northern blot analysis. - Fifteen $\mu \mathrm{g}$ of total RNA were loaded and separated on $1 \%$ formaldehyde agarose gels and transferred to the Hybond N+ membranes (Sambrook et al 1989). Northern blots were probed with chemilluminescent labeling (DIG Products, Roche, Germany) hybridized with selected cDNA clones.

Genomic DNA extraction and construction of a genomic library of $\mathrm{B}$. bassiana.-B. bassiana was cultured in PDA plates at $26 \mathrm{C}$ for $3-5 \mathrm{~d}$. The fungal culture was frozen and ground in liquid nitrogen. DNA was extracted with the extraction buffer and purified by phenol/chloroform extraction, ethanol/sodium acetate precipitation, desalted in $70 \%$ ethanol, air dried and resuspended in pure water (dos Reis et al 2004). B. bassiana genomic DNA was partially digested with the restriction enzyme Sau3AI. The DNA fragments were size fractionated on an agarose gel, and $5-8 \mathrm{~kb}$ fragments were excised and purified with the QIAEX II gel extraction kit (QIAGEN, Valencia, California) and inserted into the BamHI site of the Zap Express vector (Strategene, La Jolla, California) to construct a genomic library.

The A43 gene full sequence isolation.-The full sequence of the gene represented by clone A43 was isolated using a PCR method with the genomic library as a template (Weld and Ridgway 2005). Two pairs of primers were designed for amplification of the A43 gene, each pair consisting of one primer specific to the sequence of clone A43 and the other primer specific to the phage vector sequence flanking the insert site. They are 43F1: 5'-GCCTCTGAGGTCTTTGAG TACGAA-3'; BK: 5' -ACAGGAAACAGCTATGACCTTG-3' and 43R1: 5'-CATAGAGGGCGTTGTGGACGAAAT-3'; T7: 5'-GTAATACGACTCACTATAGGGC-3' . Both PCR products 

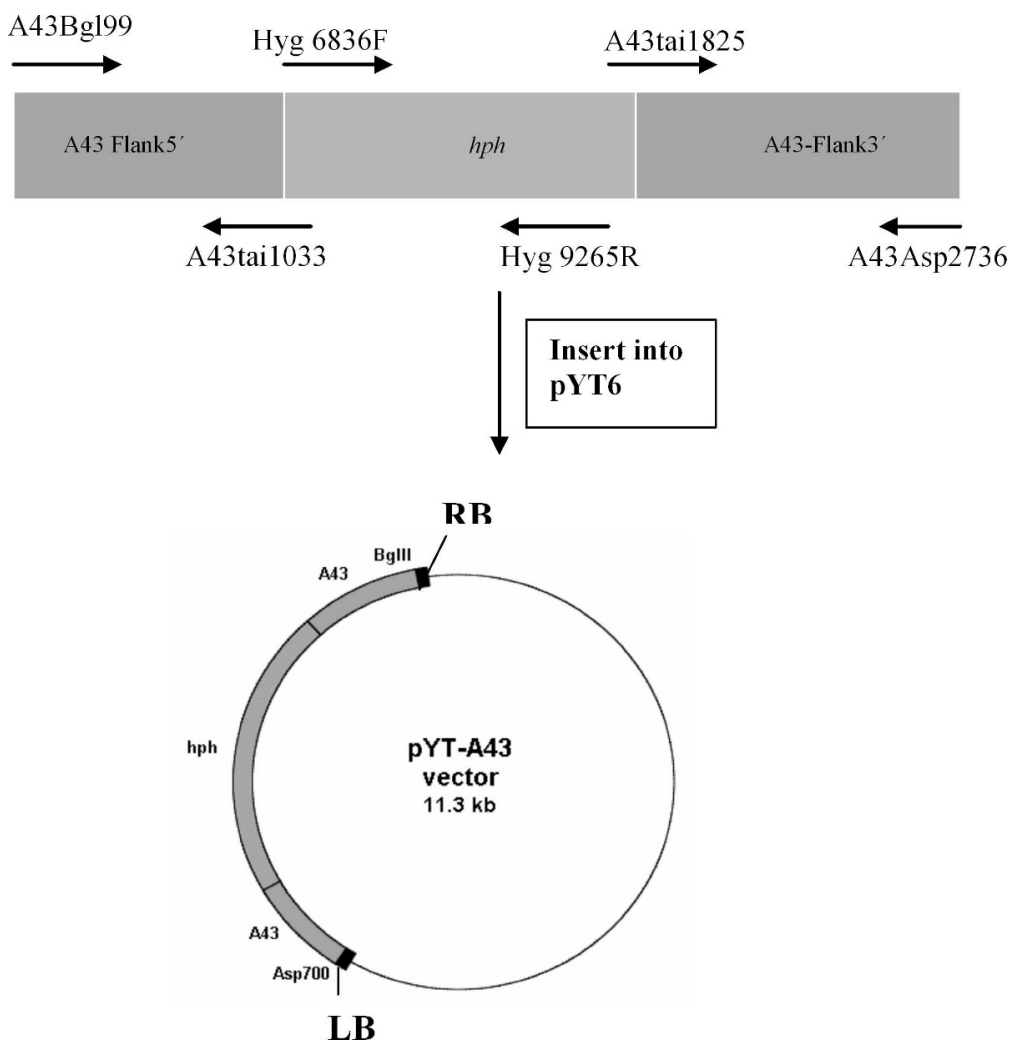

FIG. 1. Construction of the A43 gene knock-out vector. Three sets of primers were used to amplify three fragments of DNA as indicated by arrows. The whole fragment was amplified with A43Bgl99 and A43Asp2736 primers, digested with BglII and Asp700 restriction enzymes and inserted into binary vector pYT6 to form pYT-A43.

were purified and sequenced. The sequences were aligned to give the complete gene, which was cloned into pGEM-T Easy vector.

The coding region of the A43 gene was confirmed with $5^{\prime}$ and $3^{\prime}$ rapid amplification of cDNA ends (RACE) PCR kit (Roche, Germany). The $5^{\prime}$ end primers are SP1: $5^{\prime}$ GAAAGTCCTTCATGA ACTCGACCG-3' and SP2: 5'-CAT AGAGGGCGTTGTGGACGAAAT- $3^{\prime}$. The $3^{\prime}$ end primer is SP5: 5'-GCCTCTGAGGTCTTTGAGTACGAA- ${ }^{\prime}$. The amplified fragment was cloned into pGEM-T Easy vector and sequenced. The sequence of the $5^{\prime}$ - and 3 '- end cDNA was aligned with the sequence of the A43 SSH cDNA fragment and the A43 genomic sequence to verify that the newly isolated fragment belong to the correct gene.

Binary vector construction and A. tumefaciens-mediated transformation of B. bassiana.-A gene replacement construct, consisting of a hygromycin cassette flanked by the region upstream and downstream of the A43 coding region, was made with overlap extension PCR (Ho et al 1989) with the following three sets of primers. The first set amplified the $5^{\prime}$ portion of the target A43 gene with a pair of oligonucleotides, A43Bg199: 5'-AGATCTCAGAAGCT CATCTGCCATCATG-3' (restriction enzyme underlined) and A43tai1033: 5'-CCCAGATAAGGGAATTAGGGTTCC CATGATGTCCAAACGTCG-3'. PCR with this pair of primers obtained $934 \mathrm{bp}$ of the $5^{\prime}$ portion of the A43 gene fragment. The second set amplified the hygromycin B resistance gene isolated from binary vector pYT6 (pYT6 was constructed from the pCAMBIA1380 with a HindIII/XhoI fragment, containing the hygromycin $\mathrm{B}$ resistance gene [hph] under control of the Aspergillus glaA promoter and the $\operatorname{trpC}$ terminator, ligated into the T-DNA) by PCR with a pair of primers hyg6836F (5'-GGAACCCTAAT TCCCTTATCTGGG-3') and hyg9265R (5'-CCATGGTG GACTCCTCTTAAAGCTT- $3^{\prime}$ ). The third set of primers was A43tai1825: 5'-AAGCTTTAAGAGGAGTCCACCATGGCC GTGTAATTTGTTGTTCCTCG-3' and A43asp2736: $5^{\prime}$ GAATTAATTCTAGCCATCCACTTGAGGACGCA-3'. These primers amplified 911 bp of the $3^{\prime}$ portion of the A43 gene. All three PCR products were gel purified with the MinElute Gel Extraction Kit (QIAGEN, Valencia, California). These three products were mixed and used as a DNA template for PCR with the primers A43Bgl99: 5'-AGATCTCAGAAGCT CATCTGCCATCATG-3' and A43asp2736: 5' ${ }^{\prime}$-GAAT TAATTCTAGCCATCCACTTGAGGACGCA- $3^{\prime}$. The PCR conditions were $94 \mathrm{C}$ for $2 \mathrm{~min}$, then with 30 cycles of $94 \mathrm{C}$ for $30 \mathrm{~s}, 60 \mathrm{C}$ for $30 \mathrm{~s}$ and $68 \mathrm{C}$ for $4 \mathrm{~min}$, and then $68 \mathrm{C}$ extension for $7 \mathrm{~min}$. The PCR product was cloned into pGEM-T Easy vector. The plasmid was digested with the $B g l$ II and $A s p 700$ and the fragment was ligated into the pYT6 digested with $B g I I$ and Asp700 to construct pYT43hyg that was used for gene disruption (FIG. 1).

The resulting construct pYT43hyg was electroporated into A. tumefaciens EHA105 strain and used to transform $B$. 
bassiana based on the methods described by Leclerque et al (2004) and de Groot et al (1998) with modification. A colony of A. tumefaciens EHA105 containing pYT43hyg was grown at $28 \mathrm{C}$ overnight in LB broth supplemented with $50 \mu \mathrm{g} / \mathrm{mL}$ kanamycin and $25 \mu \mathrm{g} / \mathrm{mL}$ rifampicin. The $A$. tumefaciens overnight culture was diluted in minimal medium (MM) (de Groot et al 1998) supplemented with $50 \mu \mathrm{g} / \mathrm{mL}$ kanamycin and $25 \mu \mathrm{g} / \mathrm{mL}$ rifampicin and incubated at $28 \mathrm{C}$ overnight. The bacteria cells were collected by centrifugation at $5000 \mathrm{rpm}$ for $5 \mathrm{~min}$ and diluted to an optical density at $600 \mathrm{~nm}$ of 0.15 in induction medium (IM) and cultured at $28 \mathrm{C}$ for $6 \mathrm{~h}$ with shaking at $200 \mathrm{rpm}$. For cocultivation the conidia were collected from $6-8 \mathrm{~d}$ old cultures of B. bassiana grown on PDA and suspended in sterile water to the concentration of approximately $10^{6}-10^{7}$ cell $/ \mathrm{mL}$. A total $100 \mu \mathrm{L}$ of the A. tumefaciens culture was mixed with $100 \mu \mathrm{L}$ of the conidia and spread onto a paper filter placed on an IM agar plate. Plates were cocultivated at $23 \mathrm{C}$ for $2 \mathrm{~d}$, and the paper filter was transferred to PDA supplemented with $100 \mu \mathrm{g} / \mathrm{mL}$ hygromycin and $200 \mu \mathrm{g} / \mathrm{mL}$ timentin, known as selection medium (SM). The putative transformants were purified by three rounds of single spore isolation on SM and PDA medium respectively. The knockout mutants were confirmed by PCR with a set of primers. They are hyg6836: 5'-GGAACCCTAATTCCCTTATCTGGG3' and 43R2850: 5'-AAGACGAGTCAGCTGTGGTG-3'. The PCR conditions were $94 \mathrm{C}$ for $2 \mathrm{~min}, 30$ cycles of $94 \mathrm{C}$ for $30 \mathrm{~s}, 60 \mathrm{C}$ for $30 \mathrm{~s}$ and $72 \mathrm{C}$ for $3 \mathrm{~min}$ and $72 \mathrm{C}$ extension for $7 \mathrm{~min}$.

Conidia counting. - The B. bassiana wild-type F418 and the $\triangle \mathrm{A} 43$ mutants were inoculated onto PDA $\left(10^{7}\right.$ conidia per plate) and cultured at 26 C. After 1, 3, 4, 7, 10, 14 d, $5 \mathrm{~mL}$ of $0.05 \%$ of Tween was added in each Petri dish and the conidia were rubbed off gently on the surface of the mycelium and collected in a tube. The conidia were counted with a serial dilution method in which the conidia suspension was serially diluted 10 -fold and cultured on PDA at $26 \mathrm{C}$ for $3 \mathrm{~d}$ and colony number was counted in each PDA plate. The conidia also were counted with a haemocytometer. For each time point and strain triplicate PDA plates were counted and averaged. To observe conidia production the two A43 knock-out mutants, random transformants and the wild strain F418 were cultured by a slide culture method (Harris 1986). After $36 \mathrm{~h}$ all strains were observed under a microscope every $2 \mathrm{~h}$ to check conidiophore and conidia formation.

\section{RESULTS}

Sequence analysis of SSH cDNA clones.-To identify genes that were differentially expressed during conidiation, a subtractive cDNA library was constructed by SSH. Ninety-three cDNA clones were obtained. The nucleotide sequences of the cDNA clones in the range of 208-531 bp were determined for an analysis of their functions. BLASTX was used to find known proteins homologous to the cDNA clones. A total of 17 unique genes were identified and their BLAST results are summarized (TABLE I). The sequence analysis showed three cDNA fragments (A7, A39 and A71) had high similarity to known genes, specifically a glucosidase, a dehydratase and a zinc finger protein. The remainder had lower or no similarity to known

TABLE I. mRNA size and DNA sequence analysis of the SSH cDNA expressed in conidiation from B. bassiana

\begin{tabular}{|c|c|c|c|c|}
\hline Clone No. & Size (bp) & E value & $\begin{array}{l}\text { Accession } \\
\text { Number }\end{array}$ & Homologous sequence in GenBank \\
\hline A7 & 478 & $1 \mathrm{e}-14$ & CAE76365 & Neurospora crassa glucan 1, 4-alpha-glucosidase \\
\hline $\mathrm{A} 15^{\mathrm{a}}$ & 434 & 0.01 & XP_681275 & Aspergillus nidulans spore-wall hydrophobin precursor [FGSC A4] \\
\hline A24 & 391 & 6.9 & CAD 16030 & Ralstonia solanacearum probable transporter transmembrane protein \\
\hline A39 & 441 & $4 \mathrm{e}-20$ & XP_792842 & $\begin{array}{l}\text { Strongylocentrotus purpuratus similar to Zinc finger protein } 268 \text { (Zinc } \\
\text { finger protein HZF3) }\end{array}$ \\
\hline A43 & 355 & 0.17 & NP_636172 & Dictyostelium discoideum AX4 RNA-binding protein (RNP-1) \\
\hline A44 & 431 & 5.4 & CAḠ08227 & Tetraodon nigroviridis unnamed protein product \\
\hline A71 & 390 & $6 e-23$ & YP_147170 & Geobacillus kaustophilus acyl-CoA transferases/carnitine dehydratase \\
\hline B3 & 347 & 1.4 & CAE67844 & Caenorhabditis briggsae Hypothetical protein \\
\hline B20 & 392 & 2.4 & XP_955825 & Neurospora crassa hypothetical protein \\
\hline B46 & 368 & 5.3 & ZP_01310302 & Coxiella burnetii hypothetical protein \\
\hline B54 & 279 & 0.002 & XP_360844 & Magnaporthe grisea hypothetical protein \\
\hline B89 & 281 & 4.1 & ZP_01181998 & Bacillus cereus IG hypothetical protein \\
\hline C18 & 371 & & & unknown \\
\hline C26 & 279 & & & unknown \\
\hline C53 & 208 & & & unknown \\
\hline C81 & 378 & & & unknown \\
\hline C91 & 531 & & & unknown \\
\hline
\end{tabular}

${ }^{\mathrm{a}} \mathrm{A} 15$ was present in the EST library of Cho (2006). 


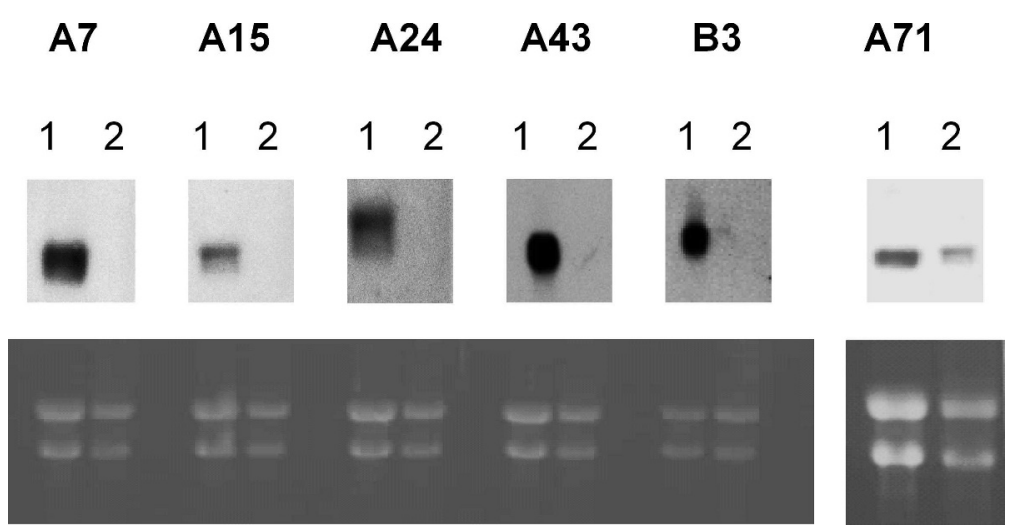

FIG. 2. Northern analysis of six selected SSH library genes. Lane 1: B. bassiana F418 sporulation culture RNA. Lane 2: B. bassiana F418 vegetative mycelium RNA. The bottom panel shows ethidium bromide stained RNA as a loading control. $15 \mu \mathrm{g}$ of total RNA per lane was loaded. The six transcripts were named A7, A15, A24, A43, B3 and A71 as illustrated in the figure.

genes. The cDNA A24 was the most highly represented transcript in the SSH library comprising $10 \%$ of the sequences and had weak similarity (E value 6.9) to transporter transmembrane protein. The cDNA A15, with medium similarity (E value 0.01 ) to a hydrophobin, was the second most represented transcript in the subtraction library.

Screening SSH clones by Northern analysis.-Nine SSH clones were selected for screening by hybridization to Northern blots carrying both conidial RNA and vegetative RNA (control). The expression patterns are shown (FIG. 2). The genes associated with five of the clones (A7, A15, A24, A43 and B3) were expressed in the conidiation stage but not in vegetative growth. One gene (A71) was expressed in both conidial and vegetative growth. Low expression was detected in remaining clones (A39, B54 and C18; data not shown). A43 gave the highest expression during conidiation in three repeat experiments and therefore was chosen for further analysis. These results indicate that the SSH library has successfully detected genes expressed during conidia formation.

Expression pattern of the A43 gene during conidiation.-To investigate the temporal expression pattern of the A43 gene, RNA representing four time points was collected for a Northern blot. The Northern blot results showed the A43 gene expression was not detected in the $48 \mathrm{~h}$ and $60 \mathrm{~h}$ samples. However by $72 \mathrm{~h}$ the A43 gene was highly expressed and continued to express in the $5 \mathrm{~d}$ sample (FIG. 3). At the same time the $B$. bassiana F418 strain was grown on PDA slide culture plates (Harris 1986) for observation of conidia formation (FIG. 3). The conidia germinated at around $36 \mathrm{~h}$ after inoculation. a.

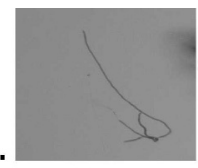

$36 \mathrm{~h}$ culture
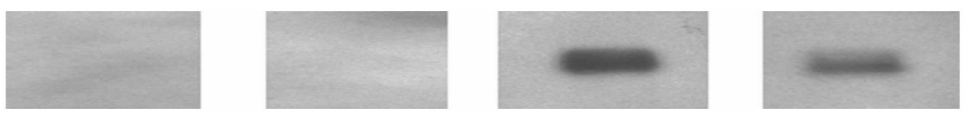

b.

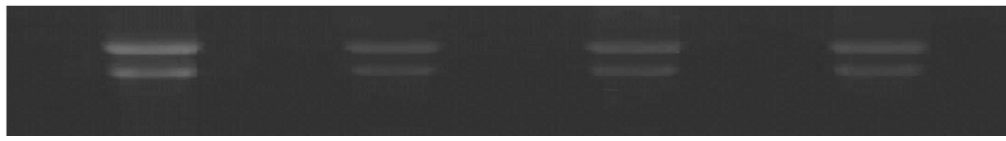

FIG. 3. Expression of the A43 gene of B. bassiana F418 during growth on PDA. a. Microscopic observation of the morphology of the fungus growth and conidia formation at four time points. b. Northern blot analysis of the A43 gene expression at four time point using A43 cDNA fragment as a probe. The bottom panel shows ethidium bromide stained RNA as a loading control. $15 \mu \mathrm{g}$ of total RNA per lane was loaded. 
WU ET AL: IDENTIFICATION OF CONIDIATION GENE

Conidial germination led to the formation of tubular hyphae that grew in polar fashion by apical extension and branching to form a network of hyphae known as a mycelium. Subsequently aerial hyphae branches were formed in the center of the colony and some of these branches subsequently differentiated into conidiophores. It took approximately $72 \mathrm{~h}$ from inoculation to the formation of new conidia. The fungal spore germination and conidia formation coincided with the A43 gene expression.

Isolation and sequencing of the complete A43 cDNA and gene.-Northern blot analysis showed that the expression of the A43 gene was consistent with a role in conidiation. Full-length cDNA and gene sequences for A43 were determined to enable a better homology search and to determine the gene structure. The 355bp fragment of A43 was used to design two genespecific oligonucleotide primers. The $5^{\prime}$ and $3^{\prime}$ end of the A43 gene were isolated with RACE-PCR to give the entire cDNA sequence (FIG. 4). The full genomic sequence of the A43 gene also was determined from a $2784 \mathrm{bp}$ DNA fragment (GenBank accession No. EF122839). Comparison of the cDNA and genomic sequences revealed two introns and a $543 \mathrm{bp}$ open reading frame, encoding a small protein of 180 amino acids, which has an estimated molecular mass $20.8 \mathrm{kDa}$ with an isoelectric point of 4.98 (FIG. 4). A putative polyadenylation signal, AATAAA, was found $36 \mathrm{bp}$ downstream from the termination codon. The CCAAT sequence was present 132 bp upstream from the putative initiation codon. The TATA box was also located $117 \mathrm{bp}$ upstream from start codon. The full cDNA sequence was used for BLASTX and showed $34 \%$ identity with a part of a RNA-binding protein.

Disruption of the B. bassiana A43 gene.-To investigate the potential role of the A43 gene in B. bassiana, a knock-out vector was constructed by replacing the coding region of the A43 gene with a $2.4 \mathrm{~kb}$ hygromicin B resistance gene $(h p h)$ isolated from vector pYT6, and introduced into B. bassiana F418 to disrupt the ORF of the A43 gene by homologous recombination. Thirty-five putative transformants were obtained and their genomic DNA was extracted from the transformant mycelium for PCR. PCR results showed two transformants produced a band of the appropriate size, indicating that a gene disruption had occurred at the A43 locus by homologous recombination (FIG. 5). In knock-out transformants the A43 gene expression was not detected by Northern blot (FIG. 6).

The phenotype of the two knock-out mutants and 33 other transformants produced by random integration of the knock-out construct were observed by growing on PDA to compare with the wild-type strain
F418. The F418 conidia germinated at $36 \mathrm{~h}$, and the mycelium grew to form a white colony with numerous conidia produced after $72 \mathrm{~h}$. The random transformants with the $h p h$ gene showed the same phenotype as the F418, which indicated the expression of the $h p h$ gene has no effect on phenotype. However the two $\triangle \mathrm{A} 43$ mutants showed phenotypic changes on PDA, with the hyphae growing vigorously to produce more floccous mycelium than the wild-type F418 (FIG. 6). The $\Delta \mathrm{A} 43$ mutants took $82 \mathrm{~h}$ to form conidiophores and produce conidia, which was about a $10 \mathrm{~h}$ delay in conidiation compared with the wild-type F418. Quantification of the conidia revealed that the number of conidia produced by $\Delta \mathrm{A} 43$ was only half that of the wild-type F418 for each time point (FIG. 7). For further confirmation that the phenotypic change of the $\Delta \mathrm{A} 43$ mutants was caused by disruption of the A43 gene, a reverse complementation of the mutant to restore the A43 gene would be worthwhile. However this transformation system is not available in our laboratory. We have characterized the two $\Delta \mathrm{A} 43$ mutants and found the same phenotypic change in the two knock-outs, which indicated that this phenotypic change is less likely to be due to other random mutations.

\section{DISCUSSION}

For the first time the SSH method was used to characterize and identify conidiation genes in $B$. bassiana. Sequence analysis of cDNA clones has revealed 17 unique $B$. bassiana genes potentially involved in conidia production. Six genes were shown by northern analysis to be upregulated during conidiation. Of these the A43 gene, which encoded a protein with $34 \%$ identity to a part of a RNA-binding region-containing protein, gave the highest expression during conidiation and therefore was analyzed further. The A43 gene had a temporal expression pattern consistent with a role in conidiation, and a knock-out mutation of this gene caused both a delay in conidia formation and a reduction in the number of conidia produced. There is evidence that other RNA binding proteins have roles in conidiation. For example over expression of a gene $f a b M$, predicted to encode a polyA binding protein (PABP), in vegetative hyphae of Aspergillus resulted in production of conidia from hyphal tips (Marhoul and Adams 1996). PABPs also have been proposed to provide means for developmentally regulated translation of specific genes in other organisms (Bandziulis et al 1989, Tarun and Sachs 1995). A RNA-binding protein homologue RIM4 promoted sporulation-specific gene expression in Saccharomyces cerevisiae (Soushko and Mitchell 2000). RNA-binding proteins play 
GAACCAATGTAGAAARTAGTCGAGCAGAAGCTCATCTGCCATCATGACCGACACCAGTTG AATAACATGTCTAGCGATGCAAGGTCATTGTCAATGCGAAGAGGAGCAGCCCTTAACCAT AGCCGCCTAGCATCATGAARAAAGAATGCCACCTCGGAAAGCCCGTTTGAAATCACTCTT GCACCAGAGATCAGCGTGCAGGTCTAGCTGCATATGGCGAGATCGGACTTTGCCGTCGAT CGGAGACTGCGCTCACGGCAGCCGAACGACATGCTTCCCCAGGCAATATACCAAAAAGTA TCCTTAGACTACACGCTTTTAGCATTACCCGCGTCTTCAGATATGTACATCCCCCTAACT TCGTTGACTTTGCCTGTCTCACAACCTCAGCAAGTCTGCAGCAAGGCATGGCECCATAAC TACATTGGAACATGAGTGCATCATGCAAAGACAAGAGGCTGGCTGAAGTCTGCATACCCG GAGAACTTGCACATTATCTGCTGACAGTTGCGTCCTATATTCTGTTCTCTGCEGTTTCTT GCAACGTCATCTCTATGGTCCAGCCTCTGTCTCTACGTTGCTTCTCAAACTTECATGATT TAGTTGAGAATGCCACGTCATTGCAAGAGTCTTATCTTCAACGATTGAAACATGTCCTC TGCTTCGACTTCTGGTATTGCAACTATGGGCCTGCAACAATGTCTATCACATCCTGAAGG CCGACCGGCATAGCTCGAAAACGCGTTCAGCTTGCTCTCCTCAGTGTTCGCTTCGAGAGA GCCGAGAGACTCGACAACATACTCCAGTGGCGTCAGAAGTAGCAAATAGATTECTCTAAA CCGCTCGCGGATGCCGAATACTGAGGTGCGGGGAAGTTCTCACGGTCTGCAGCATAGTGC AAGCACTGGCAGCCTGTCTCGGATATGACITTGATAGTCTGGTGCCAGCGAATTAGAAGT GACGACGTTTGGACATCATGTCTCGCCTCGGACAUTTATTGAAGCAGAGAGACCACGCCA TCCGGCGCATCATTTGGTACGTACTGG|CCAATCTCTCAGCTATATAACGGCTECTTTGCC CAGAGTTTCTATGGCCGTCTCTTCGATCAACAGCAACACAATTCTACGCAAACATCAATT CTACACTCATCTGTCAAARACACTTTCTGGACATCCATCATGGCTTTTGCTCTCCCCATC

1201 CACAACCTRCCCATGGACAAGCCGGTCGCCTCTGAGGTCTTGAGTACGAAAACGAGACC $\begin{array}{llllllllllllllllllll}\mathrm{H} & \mathbb{N} & \mathrm{L} & \mathrm{F} & \mathrm{M} & \mathrm{D} & \mathrm{K} & \mathrm{P} & \mathrm{V} & \mathrm{A} & \mathrm{S} & \mathrm{F} & \mathrm{V} & \mathrm{F} & \mathrm{E} & \mathrm{Y} & \mathrm{E} & \mathbb{N} & \mathrm{E} & \mathrm{T}\end{array}$

1261 TTMTACAATTGGCTGCTCACGGAGACGGAGCGTGCCCACATTGCCAGCATGCTCAACGTG

1321 GAAAGTAAGAGAAACCAAGTCACTTGAAACCCTTCGCAGGAAGGAGAAGAAGAAGAAGAA E T

$13 B 1$ GAAGAAGAAGAATGCATGCAAATCATCGTCGGCTAACATGACGTTTCCTTCCACAGCGAG

1441 CGAGTTGAAGTTCAGGGGCAACAACTTTCTCCAGGACCGCTCCGAGTGCGGCAAGTGCGG \begin{tabular}{llllllllllllllllllll}
\hline & $L$ & $K$ & F & $R$ & $G$ & $\mathbb{N}$ & $\mathbb{N}$ & F & L & Q & D & R & S & E & C & G & K & C & G
\end{tabular}

1501 CAAGTATTCGGGCATGGACGATTTCGTCCACAACGCCCTCTATGCGGGCATCCACTCGGT

1561 CGAGTTCATGAAGGACTTTCTTCTAGGAAAGACTEAGCAGGCCACCCCGTACACTGAGCA $\begin{array}{lllllllllllllllllllllll}\mathrm{E} & \mathrm{F} & \mathrm{M} & \mathrm{K} & \mathrm{D} & \mathrm{F} & \mathrm{L} & \mathrm{L} & \mathrm{G} & \mathrm{K} & \mathrm{T} & \mathrm{E} & \mathrm{Q} & \mathrm{A} & \mathrm{T} & \mathrm{P} & \mathrm{Y} & \mathrm{T} & \mathrm{F} & \mathrm{H}\end{array}$

1621 CGCAGTCGTTTGCTCCCGCTGCWACACCAAGCACWATGAAAACAAGAGCTGGAACGCCTG $\begin{array}{lllllllllllllllllllll}A & V & V & C & S & R & C & D & T & K & H & D & E & N & K & S & W & K & A & W\end{array}$

1681 GCCTCCCTGGCGCAACTGGGAGCGTGTACACTTTTGGCTGGAGAGCGAGGAATCCTTTGA $\begin{array}{llllllll}P & P & R & N & W & E\end{array}$

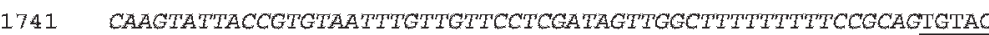
$\overline{\mathrm{I} Y}$

1801 TCGTCGAGCCAGGCACTGTGGGGCCAGAATAGCTTAGAGTGGCTAGATGCAGTACCAGCC

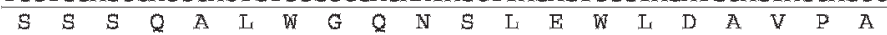
1861 ATGACGTACTACCTACCTACAGAACTGCCCGTCTTCATTCCGTGCACACTAAGCTTCTGC

$1921 \frac{\text { TGCTGATAGTTCCATATTTTTAAATGTATATATATAAAGTA AATAAAATTTCATTACAGG }}{\mathrm{C} *}$

1981 CTTGCTATATTGCCTGTATACCTGGCTGATCAGCAGATTAGCAGGCTGCAATTGTTAC 2041 GTCAAAATAATCCATCGTCACACGTGACGTTTCGAGCTCACACTCTTCCCCTTTCGGCTT 2101 ATCGGCAAGCGCAAGCTCCTGATAACGAACGGACAAGAAGTTGTCTCTCCGCGAAATTTC 2161 ATCACCAACGTCATCCCTACAGCCACATACCCAACGCCACTGCAACGCTCTCTCAACCAA 2221 ATTTTTTTGCCCCGTCGTTGCCATCTCAATCAGCCAAAATGGACATGTATGCCTTCCCAC 2281 CCGCGAGATGAACCCACTCGCGACTCGCCGCGGCGATCACGACTCGTTACGCTACGCTGT 2341 CGTGTTCCCCTCCCCCCCACCAACAGTTAAATCCCTGTGTCGACTGCATGGACAGGCTTT 2401 CCACATCTGAGCAGCGCACCCTGGAGCAGCGCATGCAGAAGCGCCAGGTCAAGGAAITCA 2461 TGGGTGTACGTGACATTTCCGGGCAGGACATTGAGCTCCCTCCCAAAAAATAAACAAAAG 2521 TTTCCCAGGAGCAAAGGCTAACTGCACACCAACCCATCAAAACAGGCTTTCGCCGGCCTC 2581 GTCGACCACTGCTTCACCTCGTGCGTCGACGACTTCACCTCCAAGGCCCTCTCATCCCGC 2611 GAAAACGGCTGCATCAACCGCTGCGTCCTCAAGTGGATGGCTACCCZGCAGCGCGTCAGC 2701 GACCGCTTCCAGGAGCACAACGCCCAGCTGTCGCAGCAGCTGCAGAACTAGGGCTGCACC 2761 ACAGCTGACTCGTCTTTTTTTTGG

FIG. 4. Nucleotide and amino acid sequences of B. bassiana F418 A43 gene. The cDNA sequence, which encodes a 180 amino acid putative protein, is underlined (GenBank accession No. EF122839). Two introns are indicated by italics. A putative polyadenylation signal, AATAAA (in box), was found in $36 \mathrm{bp}$ downstream from the termination codon. The CCAAT sequence and the TATA box (in boxes) were respectively at $132 \mathrm{bp}$ and $119 \mathrm{bp}$ upstream from the putative initiation codon. 


\section{$\begin{array}{lllllllllll}1 & 2 & 3 & 4 & 5 & 6 & 7 & 8 & 9 & 10 & 11\end{array}$}

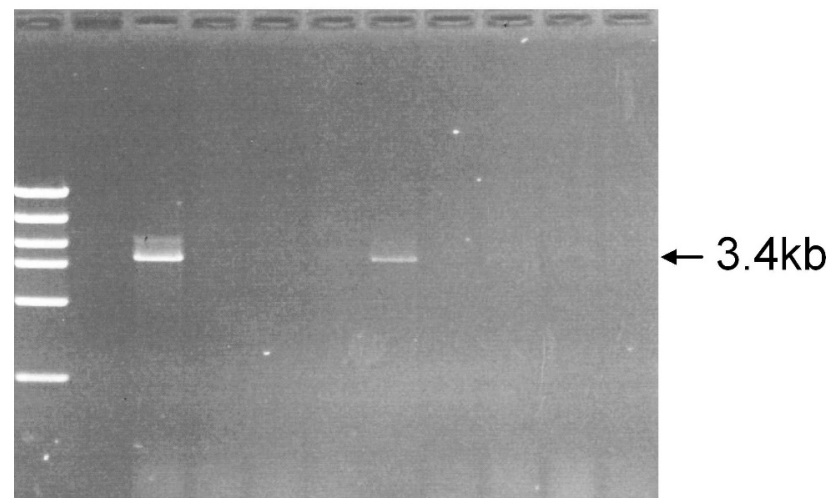

FIG. 5. Screening transformants of B. bassiana by PCR using primers Hyg6836F (from within the $h p h$ gene) and A43R2850 (from outside the $3^{\prime}$ flank of the knock-out construct) for the A43 gene knock-out mutants. Lane1: high mass marker. Lane 2: negative control (wild type strain F418). Lanes 3-10: putative transformants. Lanes 3 and 7 show the $3.4 \mathrm{~kb}$ band, indicative of a knock-out.

central roles in the post-transcriptional regulation of gene expression. Although the A43 encoded a 76aa protein, which had $34 \%$ similarity to a part of a RNA binding protein, the functional domain known to interact with RNA was not present. Therefore the

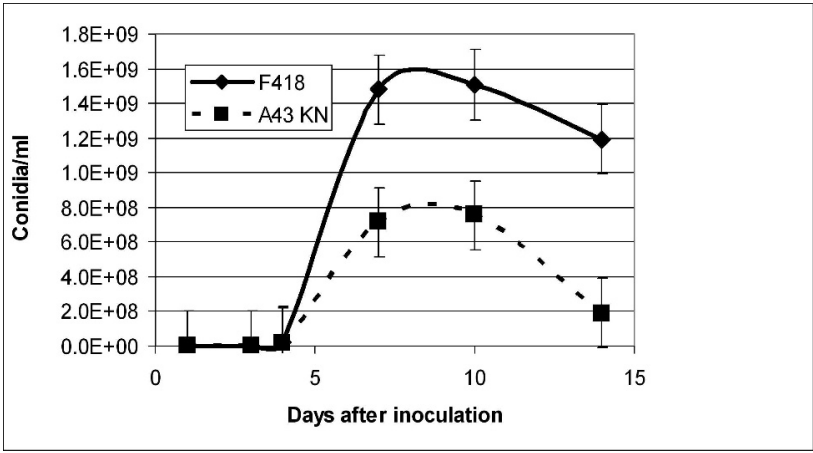

FIG. 7. Production of conidia by the strain F418 and the A43 gene knock-out mutant grown on PDA. The conidia were counted at six time points as illustrated in the figure.

specific role of the A43 gene needs further investigation.

Three of the sequences produced by SSH had significant similarity to known genes. Two EST, A7 and A71, shared high similarity to genes representing depolymerising enzymes, a glucosidase, and a dehydratase. These enzymes have been implicated in fungal virulence toward arthropods (Gupta et al 1992). They are required for cuticle degradation and establishment of fungal invasion in the target host. One EST, A39, was similar to a zinc finger
A1

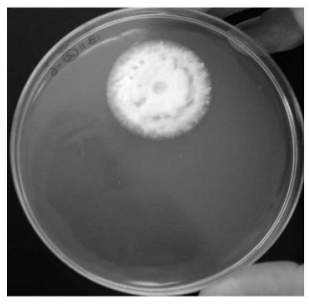

A2

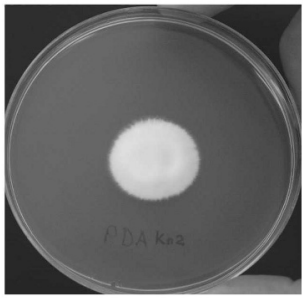

A3

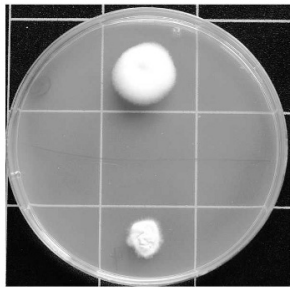

1

2

3
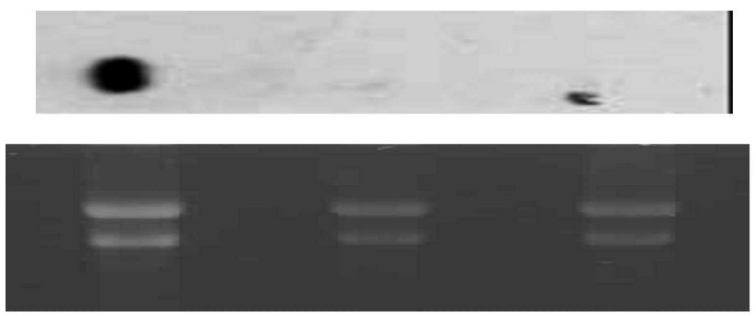

F418 KnA43 KnA43

FIG. 6. Analysis of the A43 gene knock-out. a. Morphology of wild-type strain F418 and the A43 knock-out strain grown at 26 C. A1. Wild-type strain F418 grown on PDA. A2. $\triangle$ A43 strain grown on PDA. A3. $\Delta$ A43 (top) and F418 grown on SM for 10 d. b. A43 Northern analysis. Lane 1: wild-type strain F418. Lanes 2-3: $\Delta$ A43 strains. 
protein, sharing $62 \%$ identity. Zinc finger domains are nucleic acid-binding protein structures first identified in the Xenopus laevis transcription factor, TFIIIA. These domains have been found in numerous nucleic acid-binding proteins. A zinc finger domain is composed of 25-30 amino acid residues including two conserved Cys and two conserved His residues in a C-2-C-12-H-3-H type motif. The Aspergillus nidulans brlA gene, which is essential for conidiation, encodes a zinc finger protein. BRLA is directly involved in regulating the transcription of other developmentally related genes (Boylan et al 1987, Marshall and Timberlake 1991, Chang and Timberlake1993, Andrianopolus and Timberlake 1994, Adams et al 1998). The A39 sequence and brlA shared high similarity within the conserved domain of the zinc finger protein. This indicated that A39 gene might be involved in regulating conidiation.

The two sequences that occurred most frequently in the SSH library have only weak similarity to known genes. The translated A24 sequence shared 39\% identity with a region of the transporter transmembrane protein. The transporters are multidomain membrane proteins, and they are responsible for the controlled efflux and influx of substances across cellular membranes (Higgins 1992). The cDNA A15 was expressed during conidiation and showed similarity to a hydrophobin. Hydrophobin proteins were highly expressed during the $B$. bassiana conidiation reported by Cho et al (2006). Hydrophobins are unique small molecular mass fungal proteins. In this protein family members play roles in a wide range of biological functions, including cell development and formation of aerial structure and pathogenesis (Wosten 2001, Linder et al 2005).

A number of EST (A44, B3, B20, B46, B54 and B81) shared some identity to unidentified hypothetical proteins. Also five clones showed no significant similarity to any sequence in GenBank. Few EST of B. bassiana have been reported, and with relatively little research on the fungal genes and proteins it is not unexpected that many of the fungal genes found are novel. The novelty of the gene sequences is also consistent with previous SSH studies on fungal research that produced many unknown genes (Carpenter et al 2005, Morales and Thurston 2003). However numerous genes involved in conidiation in the filamentous ascomycete $A$. nidulans have been identified and it is perhaps surprising that B. bassiana homologues were not found in this study.

In this work the SSH method was applied successfully to identify novel genes involved in conidiation of $B$. bassiana. Little was known previously about $B$. bassiana conidiation genes. Northern analysis of the A43 gene indicated the temporal expression of this novel gene was highly consistent with conidia formation. The phenotype of the $\Delta \mathrm{A} 43$ mutants was more floccus than the wild-type strain, also the number of conidia produced by the A43 knock-out mutants was less than $50 \%$ of the wild-type strain. These results indicated the A43 gene was involved in conidiation. Further studies on the identified EST should further elucidate conidial genetics in this Hyphomycete.

\section{ACKNOWLEDGMENTS}

We thank Dr Drion Boucias of the Department of Entomology and Nematology, University of Florida, for $B$. bassiana EST database analysis. We also thank Dr Richard Weld and Johanna Steyaert for valuable advice. This work was financed by the Centre of Research Excellence (CoRE), Lincoln University, New Zealand.

\section{LITERATURE CITED}

Adams TH, Boylan MT, Timberlake WE. 1988. brlA is necessary and sufficient to direct conidiophore development in Aspergillus nidulans. Cell 54:353-362.

- Wieser JK, Yu JH. 1998. Asexual sporulation in Aspergillus nidulans Microbiol Mol Biol Rev 62:35-54.

Andrianopoulos A, Timberlake WE. 1994. The Aspergillus nidulans abaA gene encodes a transcriptional activator that acts as a genetic switch to control development. Mol Cell Biol 142:503-2515.

Bandziulis RJ, Swanson MS, Dreyfuss G. 1989. RNA-binding proteins as developmental regulators. Genes Dev 3: 431-437.

Boylan MT, Mirabito PM, Willett CE, Zimmerman CR, Timberlake WE. 1987. Isolation and physical characterization of three essential conidiation genes from Aspergillus nidulans. Mol Cell Biol 17:3113-3118.

Brownbridge M, Costa S, Jaronski ST. 2001. Effect of in vitro passage of Beauveria bassiana on virulence to Bemisia argientifolii. J Invertebr Pathol 77:280-283.

Busby TM, Miller KY, Miller BL. 1996. Suppression and enhancement of the Aspergillus nidulans medusa mutation by altered dosage of the bristle and stunted genes. Genetics 143:155-63.

Butt TM, Jackson C, Magan N. 2001. Fungi as biocontrol agents CABI publishing. $15 \mathrm{p}$.

Carpenter MA, Stewart A, Ridgway HJ. 2005. Identification of novel Trichoderma hamatum genes expressed during mycoparasitism using subtractive hybridisation. FEMS Microbiol Lett 251:105-112.

Chang YC, Timberlake WE. 1993. Identification of Aspergillus brlA response elements (BREs) by genetic selection in yeast. Genetics 133:29-38.

Cho EM, Liu L, Farmerie W, Keyhani NO. 2006. EST analysis of cDNA libraries from the entomopathogenic fungus Beauveria(Cordyceps) bassiana. I. Evidence for stage-specific gene expression in aerial conidia, in vitro 
blastospores and submerged conidia. Microbiology 152:2843-2854.

de Groot MJ, Bundock P, Hooykaas PJ, Beijersbergen AG. 1998. Agrobacterium tumefaciens-mediated transformation of filamentous fungi. Nat Biotechnol 16:839-842.

de la Rosa W, Alatorre R, Barrera JF, Toreillo C. 2000. Effect of Beauveria bassiana and Metarhizium anisopliae upon the coffee berry borer (Coleoptera: Scolytidae) under field conditions. J Econ Entomol 93:1409-1414.

Diatchenko LY, Lau F, Cambell AP, Chenchik A, Moqadam F, Huang B, Lukyanov S, Gurskaya N, Sverdlov ED, Siebert PD. 1996. Suppression subtractive hybridization: a method for generating differentially regulated or tissue-specific CDNA probes and libraries. Proc Nat Acad Sci USA 93:6025-6030.

dos Reis MC, Fungaro MH, Duarte RT, Furlaneto L, Furlaneto MC. 2004. Agrobacterium tumefaciens-mediated genetic transformation of the entomopathogenic fungus Beauveria bassiana. J Microbiol Method 58:197-202.

Gish W, States DJ. 1993. Identification of protein coding regions by database similarity search. Nature Genet 3: 266-272.

Goettel MS, Eilenberg J, Glare TR. 2004. Entomopathogenic fungi and their role in regulation of insect populations. In: Comprehensive Molecular Insect Science. Vol. 6 Elsevier. p 361-406.

Gupta SC, Leathers TD, El-Sayed GN, Ignoffo CM. 1992. Insect cuticle-degrading enzymes from the entomogenous fungus Beauveria bassiana. Exp Mycol 16:132-137.

Gurskaya NG, Diatchenko L, Chenchik A, Siebert PD, Khapekov GL, Lukyanov KA, Vegner LL, Ermolaeva OD, Lukyanov SA, Sverdlov ED. 1996. Equalizing cDNA subtraction based on selective suppression of polymerase chain reaction: cloning of Jurkat cell transcripts induced by phytohemaglutinin and phorbol-12-myristate-13-acetate. Anal Biochem 240:90-97.

Harris JL. 1986. Modified method for fungal slide culture. J Clinical Microbiol 24:460-461.

Higgins CF. 1992. ABC transporters: from microorganisms to man. Ann Rev Cell Biol 8:67-113.

Ho SN, Hunt HD, Horton RM, Pullen JK, Pease LR. 1989. Site-directed mutagenesis by overlap extension using the polymerase chain-reaction. Gene 77:51-59.

Holder DJ, Keyhani NO. 2005. Adhesion of the entomopathogenic fungus Beauveria (Cordyceps) bassiana to substrata. Appl Environ Microbiol 71:5260-5266.

Jeffs LB, Xavier IJ, Matai RE, Khachatourians GG. 1999. Relationships between fungal spore morphologies and surface properties for entomopathogenic members of the genera Beauveria, Matarhizium, Paecilomyces, Tolypocladium and Verticillium. Can J Microbiol 45:936-948.

Kemp AM, Bidochka MJ. 2002. Conidium production by inset pathogenic fungi on commercially available agars. Lett Appl Microbiol 35:74-77.

Knudsen GRD, Eschen J, Dandurand LM, Wang ZG. 1991. Method to enhance growth and sporulation of pelletized biocontrol fungi. Appl Environ Mcrobiol 57:2864-2867.

Lecherous A, Wan H, Abschutz A, Chen S, Mitina GV, Zimmermann G, Schairer NU. 2004. Agrobacteriummediated insertional mutagenesis (AIM) of the en- tomopathogenic fungus Beauveria bassiana. Curr Genet 5:111-119.

Lee BN, Adams TH. 1994. The Aspergillus nidulans fluG gene is required for production of an extracellular developmental signal and is related to prokaryotic glutamine synthetase. Genes Dev 8:641-651.

Lee FJ, Moss J. 1993. An RNA-binding protein gene (RBP1) of Saccharomyces cerevisiae encodes a putative glucoserepressible protein containing two RNA recognition motifs. J Biol Chem 268:15080-15087.

Lewis LC, Bruch DJ, Gunarson RD, Bidne KG. 2001. Assessment of plant pathogenicity of endophitic Beauveria bassiana in Bt transgenic and non-transgenic corn. Crop Sci 41:1395-1400.

Li Z, Li C, Huang B, Nan N. 2001. Discovery and demonstration of the teleomorph of Beauveria bassiana (Bals) Vuill., an important entomogenous fungus. Chinese Sci Bull 46:751-753.

Linda MB, Szilvay GR, Nakari-Setala T, Penttila ME. 2005. Hydrophobics: the protein-amphiphiles of filamentous fungi. FEMS Microbiol Rev 29:877-896.

Marhoul JF, Adams TH. 1996. Aspergillus fabM encodes an essential product that is related to poly(A)-binding proteins and activates development when over expressed. Genetics 144:1463-1470.

Marshall MA, Timberlake WE. 1991. Aspergillus nidulans wet $A$ activates spore-specific gene expression. Mol Cell Biol 11:55-62.

Miller KY, Wu J, Miller BL. 1992. StuA is required for cell pattern formation in Aspergillus. Genes Dev 6:1770-1782.

Mirabito PM, Adams TH, Timberlake WE. 1989. Interactions of three sequentially expressed genes control temporal and spatial specificity in Aspergillus development. Cell 57:859-868.

Morales P, Thurston C. 2003. Efficient isolation of genes differentially expressed on cellulose by suppression subtractive hybridization in Agaricus bisporu. Mycological Research 107:401-407.

Sambrook J, Fritsch EF, Maniatis T. 1989. Molecular cloning - a laboratory manual. 2nd ed. New York: Cold Spring Harbor Laboratory Press.

Soushko M, Mitchell AP. 2000. An RNA-binding protein homologue that promotes sporulation-specific gene expression in Saccharomyces cerevisiae. Yeast 16:631-639.

Tarun SZ Jr, Sachs AB. 1995. A common function for mRNA $5^{\prime}$ and $3^{\prime}$ ends in translation initiation in yeast. Genes Dev 23:2997-3007.

Thomas KC, Khachatourians GG, Ingledew WM. 1987. Production and properties of Beauveria bassiana conidia cultivated in submerged culture Can J. Microbiol 33:12-20.

von Stein OD, Thies WG, Hofmann M. 1997. A high throughput screening for rarely transcribed differentially expressed genes. Nucleic Acid Res 25:2598-2602.

Wagner B, Lewis LC. 2000. Colonization of corn, Zea mays, by the entomopathogenic fungus Beauveria bassiana. Appl Environ Microbiol 66:3468-3473.

Weld RJ, Ridgway HJ. 2005. Extending AFLP sequences by long template PCR amplification of a fungal genomic library. BioTechniques 38:372-374. 
White JF, Belanger F, Meyer W, Sullian RF, Bischoff JF, Lewis EA. 2002. Clavicipitalean, fungal epibionts and endophytes-development of symbiotic interactions with plants. Symbiosis 33:201-213.

Wieser J, Lee BN, Fondon J, Adams TH. 1994. Genetic requirements for initiating asexual development in Aspergillus nidulans. Curr Genet 27:62-69.

, Adams TH. 1995. flbD encodes a Myb-like DNAbinding protein that coordinates initiation of Aspergillus nidulans conidiophore development. Genes Dev 9: 491-502.
Wosten HA. 2001. Hydrophobins: multipurpose proteins. Ann Rev Microbiol 55:625-646.

Wraight SP, Jackson MA, de Kock SL. 2001. Production, stabilization and formulation of fungal biocontrol agents. In: Butt TM, Jackson C, Magan N., eds. Fungi as biocontrol agents progress, problems and potential. UK: CAB International. p 253-287.

Ying SH, Feng MG. 2006. Medium component and culture conditions affect the thermotolerance of aerial conidia of fungal biocontrol agent Beauveria bassiana. Lett Appl Microbiol 43:331-335. 